\title{
Impact of Temperature Variation on the Coefficient of Thermal Expansion of Selected Rocks from South African Platinum Mines in an Unconfined Conditions
}

\author{
G. O. Oniyide \\ Department of Mining Engineering, Federal University of Technology, \\ Akure, Ondo State, Nigeria
}

\begin{abstract}
This paper presents the results of the study on the impact of temperature variation on the coefficient of thermal expansion of selected rocks from the South African platinum mines. These mines are witnessing increasing temperatures with higher depth due to high-temperature gradient. The experiment on the rock samples was done using a special set up comprising a variac, oven, digital thermometer, digital video extensometer, etc. under varying temperatures $\left(20\right.$ to $\left.140^{\circ} \mathrm{C}\right)$. The results of the laboratory tests. It is observed that the coefficient of linear thermal expansion increases with increasing temperature for all the samples. However, in comparison with other samples, chromitite has the lowest expansion coefficient. This was attributed to its lower strength and weak bond within the grain boundaries. The tests also show that temperature has an influence on the failure of crack generation and extension, which caused expansion of rocks. It is an indication that as mining depth increases in platinum mines, there is a possibility of an increase in tensile failure, which is not only a product of increased insitu stresses but temperature. The future design of deeper and hotter mines would also hugely benefit from the knowledge of rock's response to thermal stresses derived from laboratory tests.
\end{abstract}

Keywords: Temperature testing, thermal expansion, platinum mines

DOI: $10.7176 /$ ISDE/10-4-02

Publication date:May $31^{\text {st }} 2019$

\section{INTRODUCTION}

Knowledge of thermal properties and behaviour of rock has become increasingly important. Some of the processes requiring the knowledge of thermal properties include management of geothermal reservoirs, thermal methods of enhanced oil recovery, underground disposal of nuclear waste and modelling of underground mine openings. Thermal properties of greatest importance include thermal conductivity, heat capacity, and thermal diffusivity. These properties are generally not invariant but are dependent on temperature and to some extent on pressure.

Coefficient of thermal expansion is another important parameter that is used to evaluate the response of rock to variation in temperature. It can be linear or volumetric. The linear coefficient of thermal expansion, $\alpha$, is the ratio of change in length to the original length per unit of temperature change, as expressed in equation 1

$\alpha=(\Delta \mathrm{l} / \Delta \mathrm{T}) .1 / 1$

Where,

$\Delta \mathrm{l}=$ change in length of the rock specimen

$\Delta \mathrm{T}=$ change in temperature

$1=$ original length of the rock specimen

Equation 2 gives the volumetric coefficient of thermal expansion, $\beta$, which is the ratio of change in volume to the original volume per unit of temperature change, as expressed in equation 2

$\beta=(\Delta \mathrm{v} / \Delta \mathrm{T}) .1 / \mathrm{v}$

Where,

$\Delta \mathrm{v}=$ change in volume of the rock specimen

$\Delta \mathrm{T}=$ change in temperature

$\mathrm{v}=$ original volume of the rock specimen.

Huotari and Kukkonen (2004) stated the relationship between the linear and volumetric coefficient of thermal expansion as:

$\beta=3 \alpha$

According to Siegesmund et al. (2000), thermal expansion of rocks is influenced by properties such as mineral composition, texture, porosity, properties of the fluid in pores, micro-cracks, pressure, and temperature. Wong and Brace (1979) studied the effect of confining pressure on the coefficient of thermal expansion of quartzite and limestone. They affirmed that the coefficient of thermal expansion decreases with increasing confinement as shown in Figure 1. This is due to higher confining pressures that impede crack formation and extension.

From Figure 1, it is observed that though higher confining pressure caused a reduction in the coefficient of 
thermal expansion, however, the effect is insignificant, except at higher pressure, above $600 \mathrm{MPa}$. For example, a pressure increase of $100 \mathrm{MPa}$ only yields a 5\% reduction in the coefficient of thermal expansion. Wong and Brace (1979), while describing theoretical models of thermal cracking, stated that for homogeneous, isotropic material, thermal stress is absent no matter how high a temperature is applied. He further stated that only if the material is anisotropic, and if there is a mismatch in thermoelastic behaviour, will there be internal thermal stresses. These stresses result in the initiation and propagation of microcracks (Idris, 2018).

Somerton (1992) reported that the thermal expansion in the rocks is influenced by a number of factors, such as texture, constituent minerals, relative proportions of different minerals, mineral orientations, pore space, pressure, and temperature. Cooper and Simmons (1977) explained that changes in temperature result in two types of cracks: (a) thermal cycling cracks generated due to inhomogeneous strain by the mismatch of thermal expansion boundaries, (b) thermal gradient cracks produced due to inhomogeneous strain resulting from differential temperature. Table 1 shows the effect of temperature on the coefficient of linear thermal expansion, $\alpha$, of some rocks. It is obvious from the table that the values of $\alpha$ increase when tested at higher temperature range, that is $35-60^{\circ} \mathrm{C}$, except for porfyric granodiorite. Table 2 shows the volumetric and linear thermal expansion coefficient of some rocks. Looking at the values of $\alpha$ in Tables 1 and 2, it is observed that the $\alpha$ may vary within the rock types in the igneous, sedimentary or metamorphic rocks. Huotari and Kukkonen (2004) explained that such variation may be attributed to changes in texture, constituent minerals, mineral proportions, pore space, grain sizes, the orientation of minerals and fractures.

Figure 2 shows that $\alpha$ increases with increasing temperature. It also shows that heating rate has a significant influence on the expansion of rocks. According to Richter and Simmons (1974), thermal expansion of rock is affected by heating rate and the presence of micro-cracks in the sample. They suggested that heating rates not greater than $2^{\circ} \mathrm{C} / \mathrm{min}$ is required for precise measurement of thermal expansion to eliminate cracking due to stress produced by a thermal gradient. In this study, the heating rate of $2^{\circ} \mathrm{C} / \mathrm{min}$ was used for determination of the linear and volumetric coefficient of thermal expansion.

To determine the thermal expansion coefficient, two physical quantities (displacement and temperature) must be measured on a sample that is undergoing a thermal cycle. Three of the main techniques used for Coefficient of Linear Thermal Expansion (CLTE) measurement are dilatometry, interferometry, and thermomechanical analysis. Optical imaging can also be used at extreme temperatures. X-ray diffraction can be used to study changes in the lattice parameter but may not correspond to bulk thermal expansion. Mechanical dilatometry techniques are widely used. With this technique, a specimen is heated in a furnace and displacement of the ends of the specimen are transmitted to a sensor by means of push rods. The precision of the test is lower than that of interferometry, and the test is generally applicable to materials with CLTE above $5 \times 10-6 / \mathrm{K}$ over the temperature range of -180 to $900{ }^{\circ} \mathrm{C}\left(-290\right.$ to $\left.1650^{\circ} \mathrm{F}\right)$. With optical interference techniques, displacement of the specimen ends is measured in terms of the number of wave lengths of monochromatic light. Precision is significantly greater than with thermomechanical dilatometry. Thermomechanical analysis measurements are made with a thermomechanical analyzer consisting of a specimen holder and a probe that transmits changes in length to a transducer that translates movements of the probe into an electrical signal. The apparatus also consists of a furnace for uniform heating, a temperature-sensing element, calipers, and a means of recording results. The lower limit for CLTE with this method is $5 \times 10-6 / \mathrm{K}\left(2.8 \times 10-6 /{ }^{\circ} \mathrm{F}\right)$, but it may be used at lower or negative expansion levels with decreased accuracy and precision. The applicable temperature range is -120 to $600{ }^{\circ} \mathrm{C}(-$ 185 to $1110^{\circ} \mathrm{F}$ ), but the temperature range may be extended depending on instrumentation and calibration materials. According to Huotari and Kukkonen (2004), the use of weighted arithmetic means in theoretical estimation seems to give the closest value for thermal expansion coefficient compared to the measured coefficients in the literature.

The thermal expansion of rocks is important in many geophysical, mining and geothermal applications. Among other factors, the long-term structural stability of underground openings depends on the thermal stresses produced by temperature changes during geothermal energy generation (Thirumalai and Demou, 1973).

Increasing depth of mining in underground mines brings about the challenges related to heat, in-situ stresses, and logistical issues. Heat associated problems have mainly focused on the side effect of heat on workers' health (heat-stroke), increasing production costs as a result of the higher cost of ventilation due to cooling and refrigeration. The effect of increasing temperature with increasing depth on the behavior of rock has not been given much consideration. The platinum mines are in the Bushveld Igneous Complex (BIC), which is located in the northern part of South Africa. The BIC is the world's largest layered intrusion. It is about seven to nine kilometers thick and is divided into eastern, western and northern limbs. Its upper critical zone hosts the world's largest deposit of platinum group elements (PGE), (Schouwstra and Kinloch, 2000). Geological exploration information revealed the possibility of the platinum mines going for ultra-deep mining in the future. Schouwstra and Kinloch (2000) stated that the Merensky Reef has been traced for $300 \mathrm{~km}$ around the entire outcrop of the eastern and western limbs of the BIC, and to depths of $5 \mathrm{~km}$ and beyond. Gold mines in South Africa are generally deeper than the platinum mines, however, the latter has higher temperature gradient, which makes the 
platinum mines to be much warmer as the depth of mining increases. Biffi et al (2007) made a comparison of the geothermal gradient of the Witwatersrand Basin complex known by its gold mining and the BIC and reported that a virgin rock temperature of $40^{\circ} \mathrm{C}$ will be reached at an approximate depth of $650 \mathrm{~m}$ in the BIC as compared to a depth of about $1800 \mathrm{~m}$ in the West Witwatersrand Basin complex. Donoghue (2004) stated that the virgin rock temperatures (VRT) and air temperatures increase with depth, due to the geothermal gradient and autocompression of the air column. The study of the effect of temperature on the thermal expansion of rocks would be beneficial to gold and platinum mines in South Africa and other parts of the world. However, the main focus of this study is on the South African platinum mines due to their higher temperature gradient. That is why samples to be tested for thermal expansion were selected from there.

\section{Rock samples and their sources}

The rock samples tested were obtained from four different mines located in the northern and the western limb of the BIC. The mines and the samples obtained are summarized in Table 3.

1.1 Experimental set-up for the determination of unconfined Coefficient of Linear Thermal Expansion (CLTE) The procedure for the determination of unconfined CLTE is as follows:

A. Sample preparation; Black/white markers were attached on the longitudinal direction of the cylindrical core specimens as shown in Figure 3. White markers were used for specimens with dark-colored minerals, while black markers were used for specimens withlight-colored minerals for sharp colour contrast. The markers are spaced $15 \mathrm{~mm}$ apart. Two holes were drilled in each of the specimens for the insertion of a temperature probe. The reason for having the two holes is for monitoring temperature magnitudes at the lower and upper parts of the specimens to see any significant variation. Eventually, the average of both probes was used for analysis.

B. The specimen is then placed in the oven and heated at a constant rate of $2{ }^{\circ} \mathrm{C} / \mathrm{minute}$. This heating rate was chosen to avoid any cracking due to stress produced by thermal gradient, as suggested by Richter and Simmons (1974). The control of heat was done with the aid of variac attached to the heating element in the oven (Figure 4). The temperature increase was monitored through two digital thermometers that are connected to the temperature probes on the specimen. Having two thermometers increases the accuracy of the temperature measurements. The thermometers have indicators showing the targeted temperature, the actual specimen temperature during testing and time as seen in Figure 4.

C. The thermal strain is measured with a video extensometer (version LC/XY) that is capable of measuring strain at any temperature. The principle of strain measurement uses the identification of barycenter (the distances between two markers, see Figure 5, that depends on the position of markers on the specimen in real time. The length from the centers of markers are measured with a Vernier caliper and are provided as an input during the calibration stage prior to the commencement of testing. The video extensometer software then calculates thermal strain, $\varepsilon_{t}$, which is the ratio of the change in length to the original length due to heat.

D. The specimen had to be lit up with an external light source positioned directly in front of the transparent glass of the oven for illumination purposes and better contrast. The camera was leveled carefully on the axis of the specimen and measurement of strain starts at the trigger of the temperature control switch of the variac (Figure 4). The strain and time were continuously recorded in a text file on the computer.

The temperature of the samples before being heated was approximately $25^{\circ} \mathrm{C}$. Samples were then heated up to temperatures of $50^{\circ}, 70^{\circ}, 90^{\circ}, 110^{\circ}$, and $140^{\circ} \mathrm{C}$. The heating rate of $2^{\circ} \mathrm{C} /$ minute was used, which means that the temperatures of $50^{\circ}, 70^{\circ}, 90^{\circ}, 110^{\circ}$, and $140^{\circ} \mathrm{C}$ were reached in approximately $1500,2100,2700,3300$ and 4200 seconds respectively (Figure 4). When the required temperature is achieved, the temperature is kept constant for about 20 minutes to allow for even distribution of heat within the oven and the specimen. However, this final stage causes no further thermal strain increment; therefore, the data from the final stage onwards is not included in the graphs. In order to avoid the influence of previous heating cycle on the results, separate specimens were used for each test at temperatures of $50^{\circ}, 70^{\circ}, 90^{\circ}, 110^{\circ}$, and $140^{\circ} \mathrm{C}$.

\section{RESULTS AND DISCUSSION}

The CLTE of the samples at different temperatures is calculated using equation (1).

Below is a sample calculation for mottled anorthosite

Thermal strain at $110^{\circ} \mathrm{C}=-0.000740$ (-ve sign means expansion)

Initial temperature $=25^{\circ} \mathrm{C}$

Final temperature $=110^{\circ} \mathrm{C}$

Change in temperature $=(110-25)^{\circ} \mathrm{C}=85^{\circ} \mathrm{C}$

Therefore,

$\alpha_{1}=\frac{|-0.000740164|}{110-25}=8.71 \times 10^{-6}$

Figure 6 shows a typical plot of axial strain against time for mottled anorthosite, while Table 3 shows the values of CLTE for all the specimens tested under unconfined condition. From the figure, it is observed that that 
axial or longitudinal strain increases with increasing temperature. The absolute values of thermal strain are used for plotting, though going by rock engineering convention, expansion is negative. It should be noted that at the on-set of heating, anomalous expansion/contraction was observed, which makes some of the values to be in the positive and negative range. As heating continues, specimen becomes more stable and exhibits expansion. In addition, due to testing in unconfined condition, the expansion is not as linear as those obtained in confined condition.

It is observed that CLTE increases as temperature increases. For example, the CLTE for mottled anorthosite for temperatures of $50^{\circ}, 70^{\circ}, 90^{\circ}, 110^{\circ}$, and $140^{\circ} \mathrm{C}$ are $8.13,8.32,8.58,8.71,9.14$ (Figure 6 and Table 3). The same trend is observed for rock samples (Figures A3-A10). In comparison with other samples, chromitite has the lowest CLTE. Of all the samples tested, chromitite has the lowest dilation angle, this could be due to its lower strength and Young's Modulus. Chromitite has weaker bonding within the grain boundaries and thus has lower volumetric expansion when heated or loaded.

As the rock samples were subjected to heat, bonds within the grain boundaries become weaken leading to crack generation. This is then followed by coalescence of the cracks as a result of tensile failure of samples due to expansion. Ide (1937) pointed out "As the temperature of the sample rises, the crystals expand differently in different directions, depending on their composition and orientation. This unequal expansion may be expected to cause some internal cracking to take place along the lines of greatest stress. On cooling the specimen the fractures would remain". Another effect of heat on rocks is dilatancy. Dilatancy is the process by which the volume of rock increases under stress (during deformation). It is derived from the word dilation which refers to the volume expansion of brittle rock. It corresponds to an increase of volume caused by the opening of cracks, increases in porosity, and/or microfracture of rocks Oniyide and Yilmaz (2015a).

The laboratory experiments on the measurement of ultrasonic velocity (Oniyide, 2015) revealed that when rock specimens are heated, thermal stress caused the breaking of the bond between rock minerals. The bond breakage results in generation, propagation, and coalescence of cracks. The microscopic analysis reported by Oniyide and Yilmaz (2016) shows that not all the cracks generated during the heating stage are "healed" upon cooling. The analysis also shows that repeated heating and cooling, even at lower temperatures could lead to the development of macro-fractures, as it is the case with thermal weathering of rocks. In relation to underground working conditions, when ventilation cools the excavation surfaces, the inner part of the rock (far field) remains hot and continuously radiates heat towards the exposed surface, while the surface is continuously cooled by ventilation. Such heating-cooling cycles could contribute to the degradation of rock quality. According to Oniyide and Yilmaz (2015b), it is an indication that as mining depth increases in platinum mines, there is the possibility of an increase in tensile failure, which is not only a product of increased in-situ stresses but temperature.

\section{CONCLUSION}

This paper shows that temperature has an influence on the failure of crack generation and extension, which caused a reduction in the strength of the rocks. It is an indication that as mining depth increases in platinum mines, there is a possibility of an increase in tensile failure, which is not only a product of increased in-situ stresses but temperature. This is because, from the laboratory measurement of the coefficient of thermal expansion, when the rock was heated, there was the volumetric expansion of the rocks, which is a function of the thermal cracks induced by the heat energy (thermal stress).

\section{References}

Biffi M., Stanton D., Rose H. and Pienaar D. (2007): Ventilation Strategies to Meet Future Needs of the South African Platinum Industry. The Journal of the South African Institute of Mining and Metallurgy. Vol. 107 pp. 59-66.

Cooper H.W. Simmons G. (1977): The effect of cracks on the thermal expansion of rocks. Earth and Planetary Science Letters Vol. 36 pp. 404-412.

Donoghue A. M. (2004): Occupational Health Hazards in Mining: An Overview. Occupational Medicine (London). Vol. 54 pp. 283-289.

Eugene C.R. (1988). Thermal properties of rocks. Open-File Report 88-441. United States Department of the Interior Geological Survey. p 106

Huotari T. and Kukkonen L. (2004). Thermal expansion Properties of Rocks: Literature Survey and Estimation of Thermal expansion Coefficient for Olkiluoto Mica Gneiss. Working Report 2004-04. Geological Survey of Finland. $p$

Idris M.A. (2018). Effects of Elevated Temperature on Physical and Mechanical Properties of Carbonate Rocks in South-Southern Nigeria. Mining of Mineral Deposits. Volume 12 (2018), Issue 4, pp. $20-27$

Kjørholt H. (1992): Thermal properties of rock. Work report 92-56. Helsinki, Finland: Teollisuuden Voima Oy. 15 p. +4 appendices. Site investigation. 
Oniyide G. O. (2015). Thermo-Mechanical Behaviour of Rocks from the Bushveld complex with relevance to deeper mining. PhD thesis, University of the Witwatersrand, Johannesburg, South Africa (Unpubilshed).

Oniyide G. O. and Yilmaz H. (2015a). Effect of Temperature on the Dilatancy of Rocks from the Bushveld Complex, The 13th International Congress of Rock Mechanics ISRM CONGRESS 2015 ISRM 2015.MAY 10-13, 2015 | PALAIS DES CONGRÈS DE MONTRÉAL MONTRÉAL, CANADA Innovations in Applied and Theoretical Rock Mechanics. pp. 1-10.

Oniyide G. O. and Yilmaz H. (2015b). Thermo-Mechanical Behaviour of Rocks from the South African Platinum Mines, 24th International Mining Congress and Exhibition of Turkey, April 14-17, 2015 ANTALYA-TURKEY pp. 637-644.

Oniyide G. O. and Yilmaz H. (2016). Microscopic analyses of Bushveld Complex rocks under the influence of high temperatures. The Journal of The Southern African Institute of Mining and Metallurgy. Vol. $116 \mathrm{pp}$. 251-257.

Ramana Y.V., Sarma L.P. (1980): Thermal expansion of a few indian granitic rocks. In: Physics of the Earth and Planetary Interiors Vol. 22, pp. 36-41.

Richter D. and Simmons G. (1974): Thermal Expansion Behaviour of Igneous Rocks. Int. J. Rock Mech. Min. Sci. and Geomech. Abstr. Vol. 11, pp. 403-411.

Robertson E. C. (1988): Thermal properties of rocks. U.S. Geological Survey Open-File Report 88-441, 106 p.

Schouwstra, R.P., Kinloch, E.D., Lee, C.A. (2000). A short geological review of the Bushveld Complex. Platinum Metals Review, 44(1), 33-39.

Siegesmund S. Ullemeyer K. Weiss T. Tschegg E. K. (2000): Physical weathering of marbles caused by anisotropic thermal expansion. International Journal of Earth Sciences, Vol. 89 pp. 170-182.

Somerton, W.H. 1992. Thermal properties and temperature-related behavior of rock/fluid systems. Developments in petroleum science, 37. Amsterdam, Netherlands: Elsevier Science publishers B.V. 257 p

Thirumalai, K. and Demou, S.G., 1973. Thermal expansion behaviour of intact and thermally fractured mine rocks. In: R.E. Taylor and G.L. Denman (Editors), Am. Inst. Phys. Conf. Proc., 17.

Wong $T$ and Brace W.F. (1979) Thermal Expansion of Rocks: Some Measurements at High Pressure. Tectonophysics 57:95-117.

\section{Notes}

Note 1. This is an example.

Note 2. This is an example for note 2

Table 1: Thermal expansion of some rocks with increasing temperature (Kjørholt, 1992)

\begin{tabular}{|l|c|c|c|c|}
\hline \multicolumn{4}{|c|}{ Average coefficient of linear thermal expansion, $\alpha\left(10^{-6} \mathrm{per}^{\circ} \mathrm{C}\right)$} \\
\hline Rocks & Rock type & $10-35^{\circ} \mathrm{C}$ & $35-60^{\circ} \mathrm{C}$ & $10-60^{\circ} \mathrm{C}$ \\
\hline Tonalite gneiss & Metamorphic & 6.6 & 9.7 & 8.1 \\
\hline Mica gneiss & Metamorphic & 8.2 & 10.9 & 9.5 \\
\hline Tonalite & Igneous & 6.6 & 8.8 & 7.7 \\
\hline Porfyric granite & Igneous & 7.3 & 10.4 & 8.8 \\
\hline Porfyric granodiorite & Igneous & 9.3 & 8.1 & 8.7 \\
\hline
\end{tabular}

Table 2: Volumetric and linear thermal expansion coefficient of some rocks (Robertson, 1988)

\begin{tabular}{|l|c|c|c|}
\hline \multicolumn{1}{|c|}{ Rocks } & Rock type & $\begin{array}{c}\text { Volumetric thermal expansion } \\
\text { coefficient } \\
\left(10^{-5} \text { per }{ }^{\circ} \mathrm{C}\right)\end{array}$ & $\begin{array}{c}\text { Linear thermal expansion } \\
\text { coefficient } \\
\alpha\left(10^{-6} \text { per }{ }^{\circ} \mathrm{C}\right)\end{array}$ \\
\hline Granite, Rhyolite & Igneous & 2.4 & 8.0 \\
\hline Diorite, andesite & Igneous & 2.1 & 7.0 \\
\hline Gabbro, basalt & Igneous & 1.6 & 5.3 \\
\hline Sandstone & Sedimentary & 3.0 & 10 \\
\hline Limestone & Sedimentary & 2.4 & 8.0 \\
\hline Marble & Metamorphic & 2.1 & 7.0 \\
\hline Slate & Metamorphic & 2.7 & 9.0 \\
\hline Quartzite & Metamorphic & 3.3 & 11 \\
\hline
\end{tabular}


Table 3: Details of the samples received from different mines

\begin{tabular}{|l|l|l|l|l|l|}
\hline S/N & Mines & Company & $\begin{array}{l}\text { BIC } \\
\text { location }\end{array}$ & Rocks received & $\begin{array}{l}\text { Diameter } \\
(\mathrm{mm})\end{array}$ \\
\hline 1 & $\begin{array}{l}\text { Mogalakwena } \\
\text { Platinum mine }\end{array}$ & AngloAmerican Platinum & $\begin{array}{l}\text { Northern } \\
\text { limb }\end{array}$ & $\begin{array}{l}\text { GN, VTA, MA, G, } \\
\text { GF, PX }\end{array}$ & 36 \\
\hline 2 & $\begin{array}{l}\text { Bafokeng Rasimone } \\
\text { Platinum }\end{array}$ & $\begin{array}{l}\text { Royal Bafokeng Platinum } \\
\text { (BRPM) }\end{array}$ & $\begin{array}{l}\text { Western } \\
\text { limb } \\
\text { mine }\end{array}$ & $\begin{array}{l}\text { N, LN, ANCR, VTA, } \\
\text { MA, CR, PX }\end{array}$ & 36 \\
\hline 3 & $\begin{array}{l}\text { Siphumelele Platinum } \\
\text { mine }\end{array}$ & AngloAmerican Platinum & $\begin{array}{l}\text { Western } \\
\text { limb }\end{array}$ & $\begin{array}{l}\text { GN, N, LN, VTA, } \\
\text { MA, PX }\end{array}$ & 47 \\
\hline
\end{tabular}

ANCR : anorthosite-chromitite; CR : chromitite; LN : leuco-norite; MA : mottled-anorthosite;

$\mathrm{N}$ : norite; PX : pyroxenite; VTA : varitextured-anorthosite; GN : gabbro-norite; G : granite;

$\mathrm{GF}$ :granofels.

Table 3: The coefficient of linear thermal expansion $(\alpha \mathrm{l})$-unconfined

\begin{tabular}{|c|c|c|c|c|c|c|c|c|c|}
\hline \multirow[t]{2}{*}{ TEMPERATURE $\left({ }^{\circ} \mathrm{C}\right)$} & \multicolumn{9}{|c|}{$\operatorname{CLTE}\left(* 10^{-6}\right) / \mathrm{K}$} \\
\hline & CR & $\mathrm{N}$ & GN & LN & VTA & GF & MA & PX & $\mathrm{G}$ \\
\hline 50 & 7.93 & 8.25 & 7.80 & 8.06 & 8.00 & 7.74 & 8.13 & 8.14 & 7.91 \\
\hline 70 & 8.14 & 8.44 & 8.00 & 8.24 & 8.22 & 7.87 & 8.32 & 8.30 & 8.11 \\
\hline 90 & 8.37 & 8.63 & 8.22 & 8.49 & 8.41 & 7.96 & 8.58 & 8.54 & 8.31 \\
\hline 110 & 8.57 & 8.75 & 8.48 & 8.64 & 8.62 & 8.03 & 8.71 & 8.73 & 8.59 \\
\hline 140 & 8.94 & 9.16 & 9.33 & 9.09 & 9.14 & 9.02 & 9.14 & 9.05 & 9.24 \\
\hline
\end{tabular}

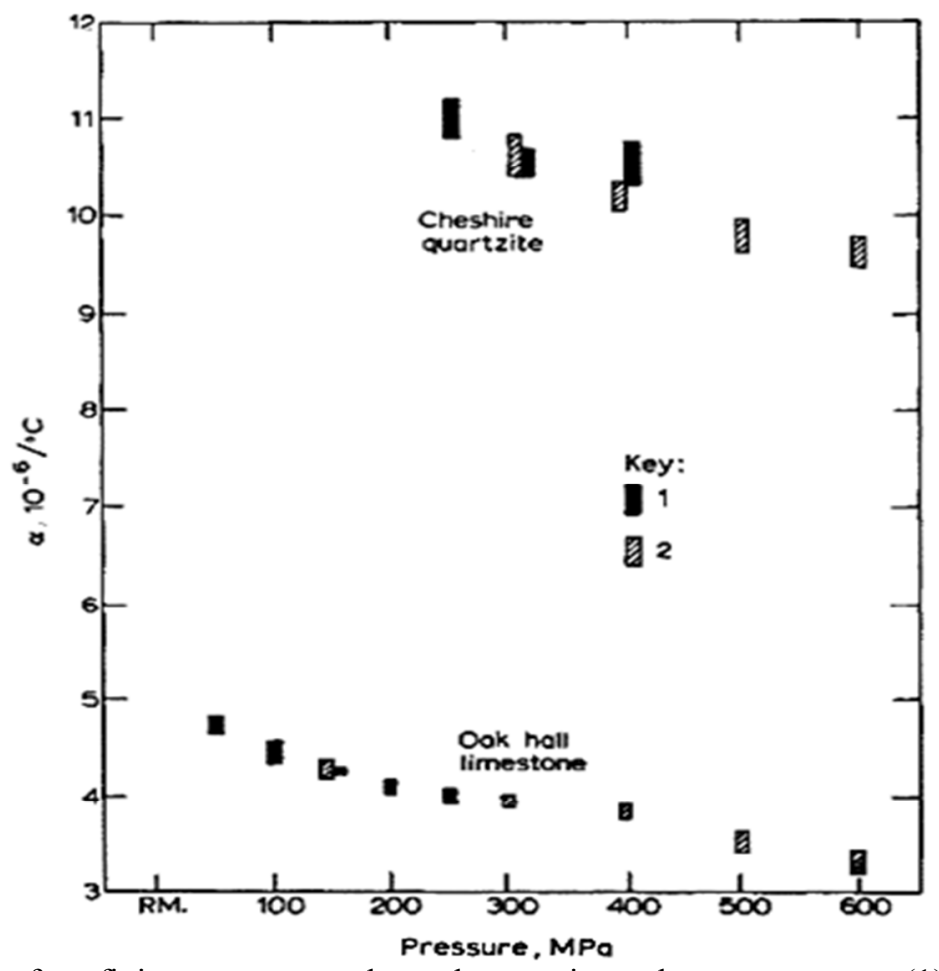

Figure 1: Influence of confining pressure on thermal expansion- when pressure was (1) decreased and (2) increased (Wong and Brace, 1979). 


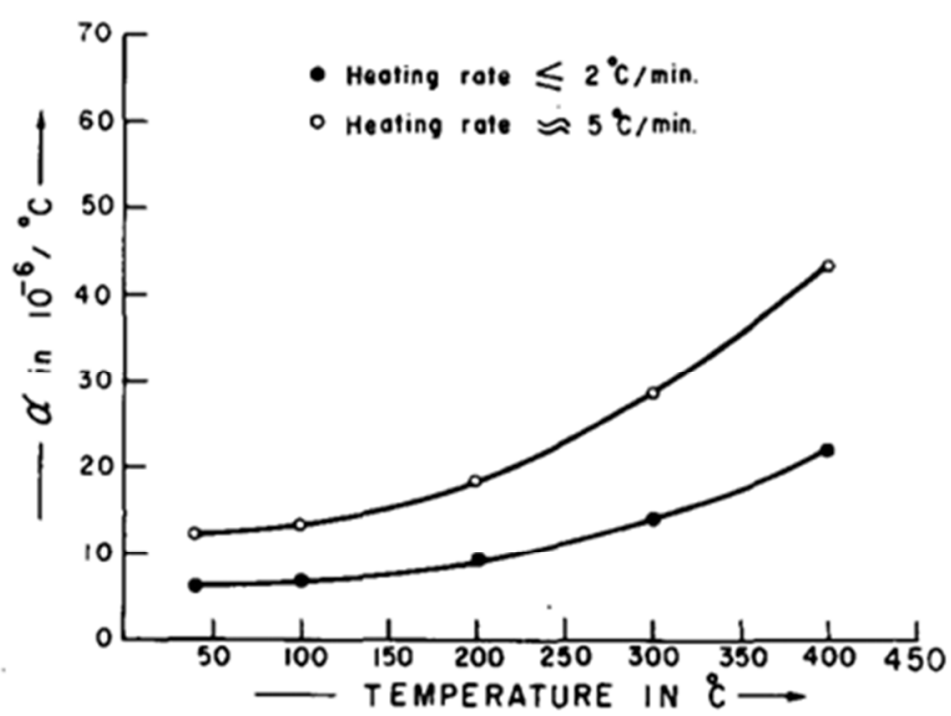

Figure 2: Effect of temperature and heating rate on coefficient of thermal expansion of granite (Ramana and Sarma, 1980).

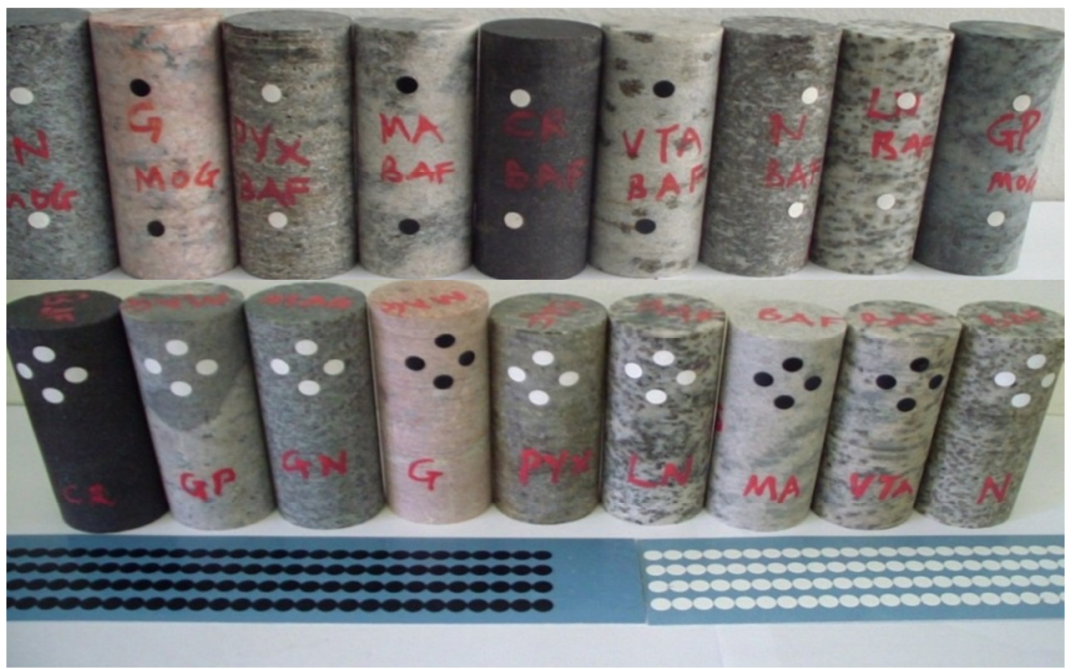

a)

b)

Figure 3: Rock specimens with markers for a) axial and b) transverse thermal strain measurements

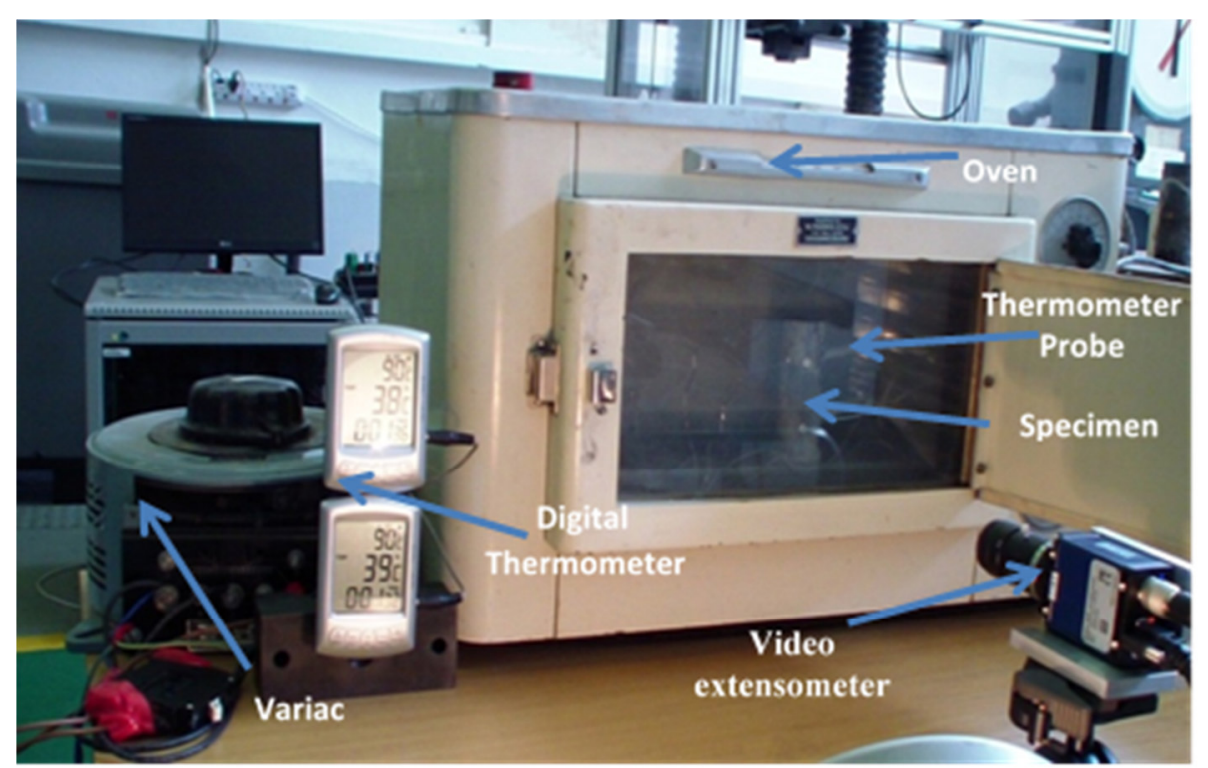

Figure 4: Experimental set-up for thermal strain measurements 


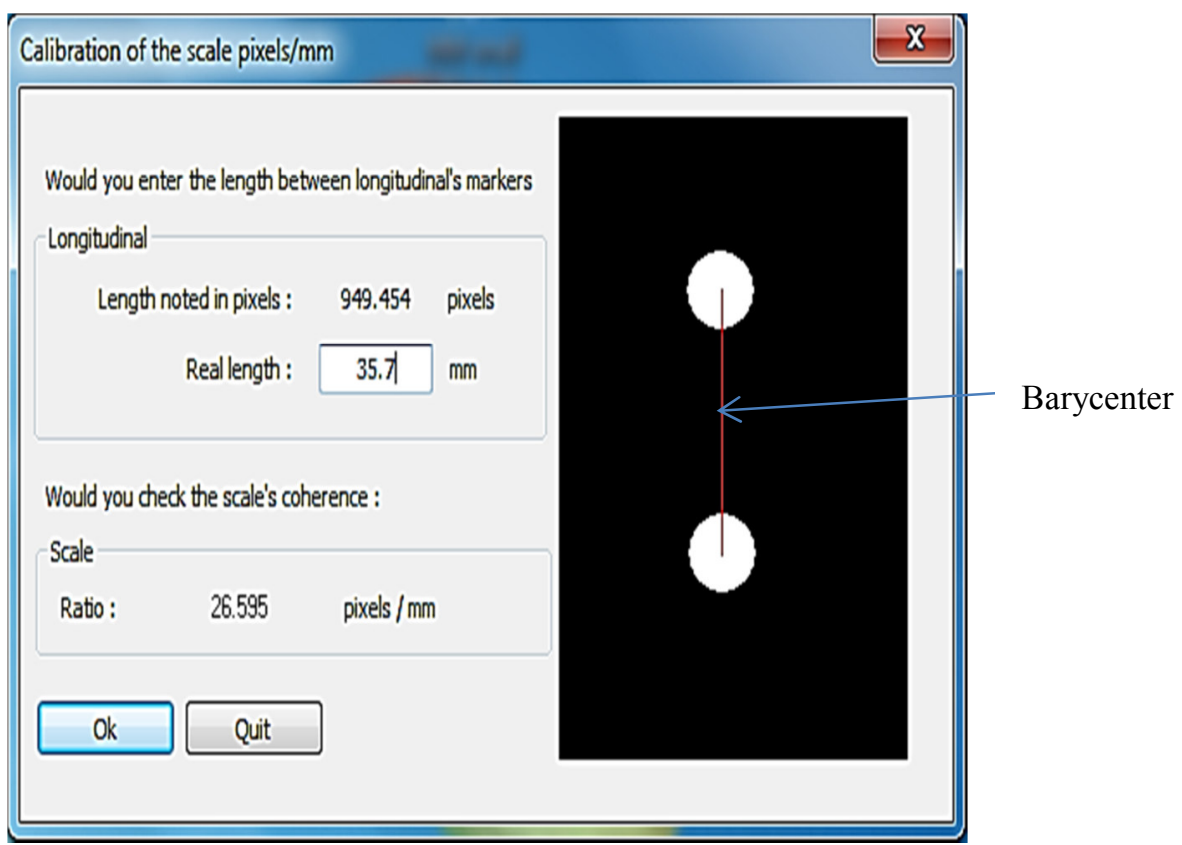

Figure 5: Principle of strain measurement using the identification of barycenter

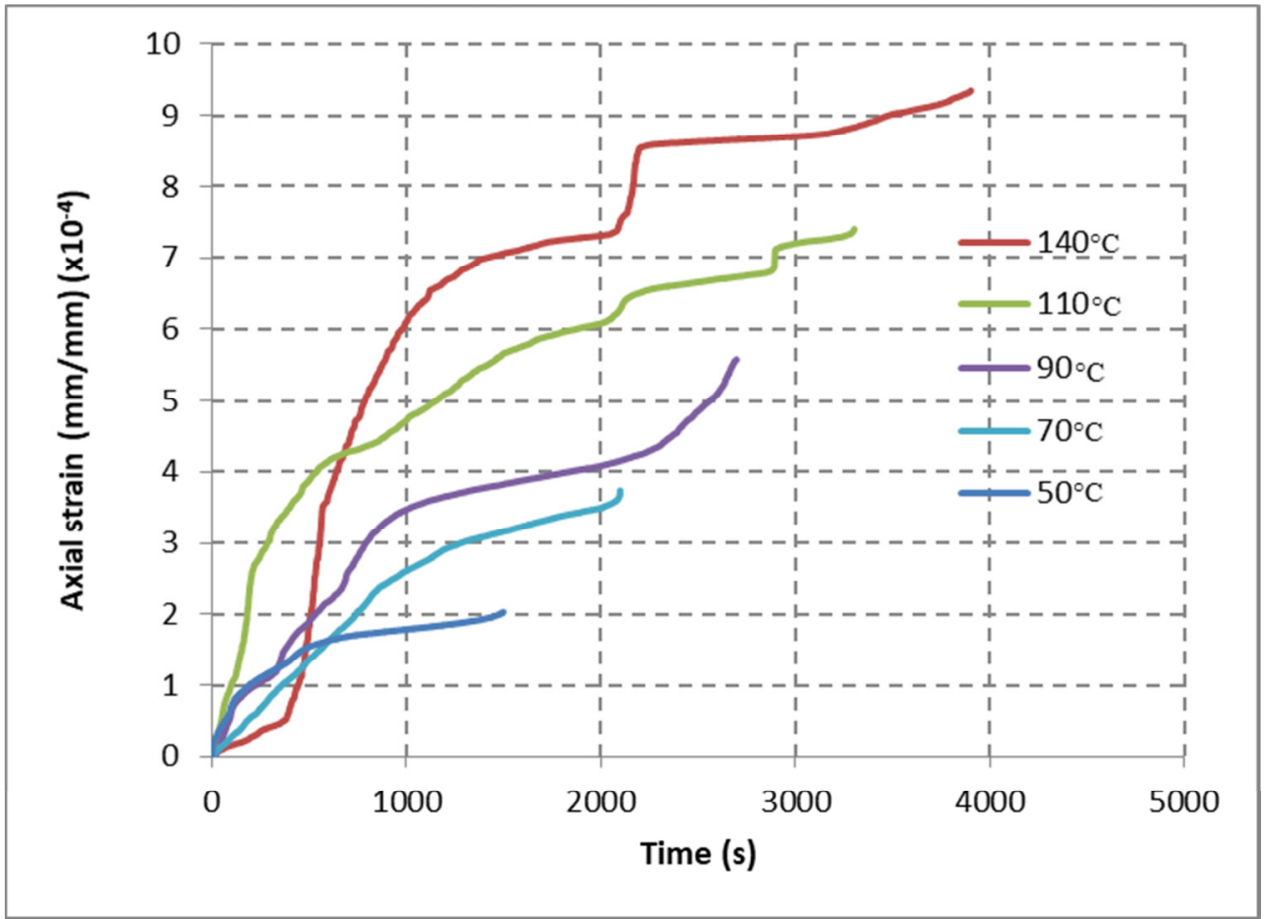

Figure 6: Axial strain versus time for mottled anorthosite at different temperatures 